

\title{
Unprecedented reverse volume expansion in spin-transition crystals
}

Wenbin Guo, Nathalie Daro, Sebastien Pillet, Mathieu Marchivie, El-Eulmi

Bendeif, Elodie Tailleur, Kittipong Chainok, Dominique Denux, Guillaume

Chastanet, Philippe Guionneau

\section{To cite this version:}

Wenbin Guo, Nathalie Daro, Sebastien Pillet, Mathieu Marchivie, El-Eulmi Bendeif, et al.. Unprecedented reverse volume expansion in spin-transition crystals. Chemistry - A European Journal, 2020, 26 (57), pp.12927-12930. 10.1002/chem.202001821 . hal-02945219

\section{HAL Id: hal-02945219 \\ https://hal.science/hal-02945219}

Submitted on 8 Oct 2020

HAL is a multi-disciplinary open access archive for the deposit and dissemination of scientific research documents, whether they are published or not. The documents may come from teaching and research institutions in France or abroad, or from public or private research centers.
L'archive ouverte pluridisciplinaire HAL, est destinée au dépôt et à la diffusion de documents scientifiques de niveau recherche, publiés ou non, émanant des établissements d'enseignement et de recherche français ou étrangers, des laboratoires publics ou privés. 


\title{
Unprecedented Reverse Volume Expansion in Spin-Transition Crystals
}

\author{
Wenbin GUO ${ }^{[a]}$, Nathalie DARO ${ }^{[a]}$, Sébastien PILLET ${ }^{[b]}$, Mathieu MARCHIVIE[ ${ }^{[a]}$, El-Eulmi BENDEIF[b], \\ Elodie TAILLEUR ${ }^{[a]}$, Kittipong CHAINOK ${ }^{[a]}$, Dominique DENUX ${ }^{[a]}$, Guillaume CHASTANET $^{\star[a]}$, Philippe \\ GUIONNEAU*[a]
}

\begin{abstract}
The current craze for research around the spin crossover phenomenon can be justified to some extent by the mechanical properties due to the decrease of volume associated with the transition of the metal ion from the HS state to the LS state. As demonstrated here, the molecular complex $\left[\mathrm{Fe}(\mathrm{PM}-p \mathrm{BrA})_{2}(\mathrm{NCS})_{2}\right]$ exhibits, on the contrary, an increase of the unit-cell volume from HS to LS. This counter-intuitive and unprecedented behavior that concerns both the thermal and the photo-excited spin conversions is_revealed by a combination of single-crystal and powder X-ray diffraction complemented by magnetic measurements. Interestingly, this abnormal volume change appears concomitant with the wide rotation of a phenyl ring which induces a drastic modification, though reversible, of the structural packing within the crystal. In addition, the light-induced HS state obtained through the Light-Induced Excited Spin-State Trapping shows a remarkably high relaxation temperature, namely $\mathrm{T}($ LIESST), of $109 \mathrm{~K}$, one of the highest so far reported. The above set of quite unusual characteristics opens up new fields of possibilities within the development of spin crossover materials.
\end{abstract}

The spin crossover (SCO), meaning the modification of the electronic configuration of transition metal ions initiated by external stimuli such as temperature, pressure, light and magnetic fields [1], currently attracts intense interests in coordination chemistry, solidstate physics and materials science [2]. The SCO in iron(II) based molecular compounds, the most studied ones, is associated to volume modifications at all physical scales [3]. In such compounds, it is very well documented that the high-spin (HS) to low-spin (LS) conversion always corresponds to a huge decrease of the iron polyhedron volume of about $25 \%$. The latter has repercussions on the crystal packing leading to a decrease of the unit-cell volume. However, due to the flexibility of the molecular and intermolecular scales the final HS-LS unit-cell

[a] W. Guo, N. Daro, M. Marchivie, K. Chainok, E. Tailleur, D. Denux G. Chastanet, P. Guionneau

CNRS, Univ. Bordeaux

Bordeaux INP, ICMCB, UMR 5026 ,

F-33600 Pessac (France)

Current address for K.C: Materials and Textiles Technology, Faculty

of Science and Technology, Thammasat University, Khlong Luang,

Pathum Thani 12121, Thailand

corresponding authors: Dr HdR Guillaume Chastanet

guillaume.chastanet@icmcb.cnrs.fr; Pr HdR Philippe Guionneau philippe.guionneau@icmcb.cnrs.fr

[b] S. Pillet, E.Bendeif

Université de Lorraine, CNRS, CRM2, Nancy,

254506 Vandoeuvre-les-Nancy, France

Supporting information includes Synthesis, Crystallization, DSC

Magnetism, Photo-magnetism, Single-crystal X-ray Diffraction,

Powder X-ray diffraction and Photo-crystallography volume decay is lower, typically into the range of $2-5 \%$ but with also some examples reaching more than $10 \%$ [4]. Besides, it is well known that the metal coordination-sphere volume modification results from a combination of bond-length and distortion modifications. The latter is known to play a crucial role in the LightInduced Spin-State Trapping (LIESST) phenomenon since huge modifications of distortion at the SCO can generate large energy barriers to relaxation, associated to high relaxation temperatures, $\mathrm{T}($ LIESST) [5]. However, the definitive structure- property relationship allowing to rationally design compounds showing very high $\mathrm{T}($ LIESST) is still to be definitely stated since other parameters than the distortion are probably to be taken into account. For instance, photo-excited states (PES) can be stabilized by elastically driven cooperativity triggered by a light pulse [6].

In the context of our efforts to explore the multiscale aspect of SCO in molecule-based materials we functionalized the Schiff base ligand of the PM-L family to tune both the coordination geometry and the intermolecular interactions [7]. The solvent-free complexes $\left[\mathrm{M}(\mathrm{PM}-\mathrm{pBrA})_{2}(\mathrm{NCS})_{2}\right](\mathrm{M}=\mathrm{Fe}(\mathbf{1})$ and $\mathrm{Mn}(\mathbf{2})$ and $\mathrm{PM}-$ $\mathrm{pBrA}=\mathrm{N}$-(2'-pyridylmethylene)-4-bromoaniline; $p$ being for para position) were crystallized. Magnetism and crystallography approaches, including photo-induced aspects, were performed. The structural investigation by $\mathrm{X}$-ray diffraction notably focused on the fine description of SCO following a protocol already reported [8]. The isomorphic and non SCO-active compound $\mathrm{Mn}(2)$ has been studied to highlight the particularity of the Fe compound (1) SCO features.

Magnetic measurements suggest (1) shows an abrupt thermal SCO with a small hysteresis loop with $T_{1 / 2} \downarrow=170.2 \mathrm{~K}$ and $T_{1 / 2} \uparrow=$ $181.4 \mathrm{~K}$, indicating the cooperative character of this compound (Figure 1). The hysteresis loop can be reproduced over successive thermal cycles under different rate (Figure S1). Moreover, the Thermally-Induced (TIESST) and Light-Induced (LIESST) Excited Spin-State Trapping allow to trap the high-spin metastable state at low temperature. These states can be kept at a relatively high temperature leading to the relaxation temperatures $\mathrm{T}($ LIESST) and $\mathrm{T}$ (TIESST) values of around $109 \mathrm{~K}$ as shown in Figure 1. $\mathrm{T}$ (TIESST) and T(LIESST) above $100 \mathrm{~K}$ are quite rare in molecular complexes [9]. Interestingly enough, (1) shows the highest $\mathrm{T}$ (LIESST) of the corresponding family of iron compounds and of bidentate-based iron(II) complexes and one of the highest reported so far within the whole literature of SCO materials [10]. This characteristic represents the first singular feature of this compound.

As shown by Single-Crystal X-ray Diffraction (SCXRD), the crystal symmetry $\left(P 2_{1} / \mathrm{n}\right)$ is not affected by temperature but the variation of the crystal lattice volume is strong at the thermal SCO and above all it reveals a very surprising behavior. Indeed, the unitcell volume increases from HS to LS (Figure 2a): from $300 \mathrm{~K}$ 
to $170 \mathrm{~K}$, the unit-cell volume decreases gradually due to thermal contraction while it increases abruptly from $170 \mathrm{~K}$ to $160 \mathrm{~K}$ at the SCO, this behavior being reversible by warming. Note that the isomorphic Mn compound (2) shows a reversible decrease of the unit-cell volume over the whole temperature range by cooling (Figure S3).

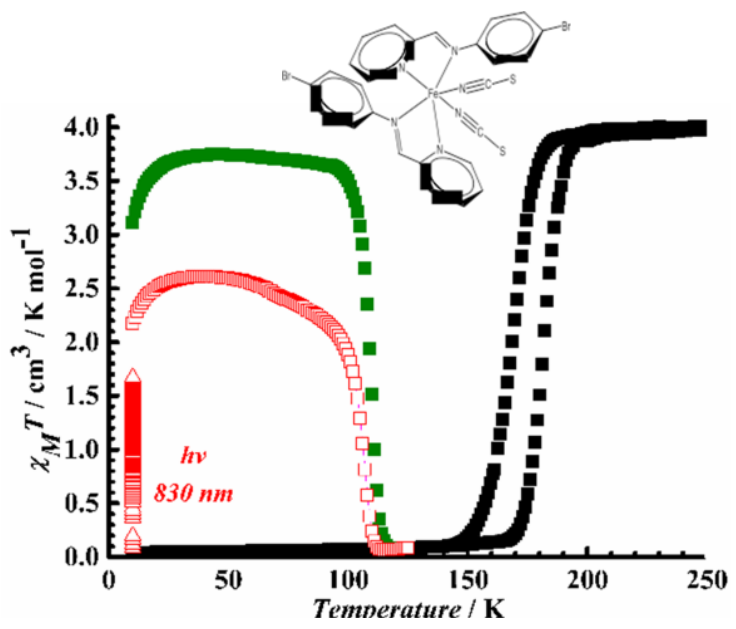

Figure 1. $\chi_{M T} \mathrm{~T}$ as a function of temperature for (1) showing the thermal SCO (black curve), the SCO after thermal quenching at 10K (green curve) and the light-induced spin-state trapping (red curve). Insert shows the scheme of the molecule.

The increase of the unit-cell volume from HS to LS, as observed here appears to be contrary to what has been observed so far for the SCO phenomenon and is also confirmed by both single crystal (Figure 2a) and Powder X-Ray Diffraction (PXRD) (Figure 2b). Note also that SCXRD, PXRD (Figure 2) and magnetism (Figure 1) are in excellent agreement in term of temperature of transition, as is DSC (Figure S7). XRD data also show the co-existence of HS and LS domains which confirms the first order nature of the transition. In the SCO temperature region, the reversible increase of volume from HS to LS results in fact from the strong anisotropy of the unit-cell modifications. As shown in Figure S2, when cooling from $200 \mathrm{~K}$ to $150 \mathrm{~K}$, the value of $a$ decreases by $4.40 \%$ while $c$ increases by $6.55 \%$. If the anisotropy of the unit-cell modifications due to the SCO is a usual fact, it may be the first time that a HS to LS conversion is observed as a positive expansion. The latter amplitude is accurately determined by comparing the volumes of the HS and LS unit-cells at the same temperature, the HS one obtained by quenching and the LS one by slow cooling. At $80 \mathrm{~K}$, the volumes of the HS (5423.8(3) $\left.\AA^{3}\right)$ and LS (5510.8(5) $\left.\AA^{3}\right)$ unit-cells confirm an increase of $1.6 \%$ from HS to LS (Table S1). Note that a reverse volume expansion, though very tiny compared to the one reported here and only observed in association to a LIESST effect, has been observed previously [11].

To shed lighlight on the very original aspects of this compound, that is, the unprecedented reverse volume modification and the very high T(LIESST), the crystal structures in the HS and LS states were determined at different temperatures and were scrutinized, including the quenched $\mathrm{HS}$ at $80 \mathrm{~K}$ and 10 $\mathrm{K}$ (Table S1).

The crystal packing is built from the asymmetric unit that contains two independent crystallographic sites for iron(II) ions, labelled hereafter $\mathrm{Fe} 1$ and $\mathrm{Fe} 2$ (Figure 3). The average of the bond lengths, $<\mathrm{Fe}-\mathrm{N}\rangle$, is 2.183(5) $\AA$ and 2.178(6) $\AA$ in $\mathrm{Fe} 1$ and

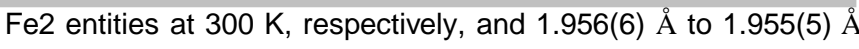
at $150 \mathrm{~K}$, showing that both have undergone a full SCO. This usual modification of bond lengths is accompanied by a huge variation of the distortion of the iron polyhedron (Table S2). The strong variation of the bond length distortion $(\zeta)$, angle distortion $(\Sigma)$ and trigonal distortion $(\Theta)$ [12] at the same temperature (Figure S4) indicate that $\mathrm{Fe} 1$ and $\mathrm{Fe} 2$ undergo the SCO concomitantly, in agreement with the magnetic measurement.

(a)

(b)
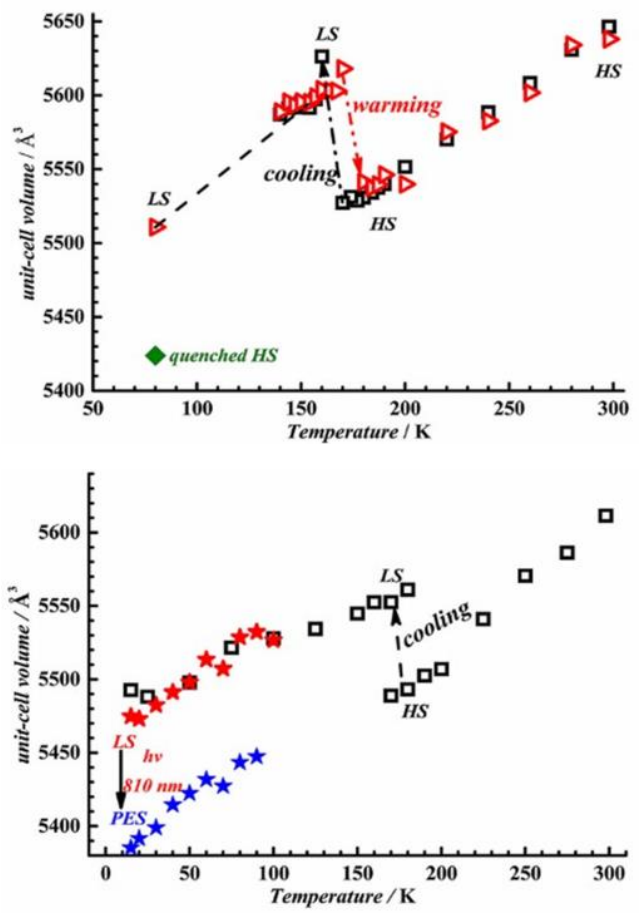

Figure 2. The temperature dependence of the unit-cell volume for (1) showing the increase from HS to LS determined by (a) SCXRD where the square and triangle represent the cooling and warming modes and where the green rhombus shows the experimental point obtained by quenching from RT to $80 \mathrm{~K}$ and by (b) PXRD where low temperature PES experimental points are figured by blue stars and relaxed LS ones by red stars. In both figures the increase of the unit-cell volume from HS to LS is evidenced. This reverse volume modification compared to the usual one is also shown by the higher volume of the LS than the HS quenched at $80 \mathrm{~K}$ in (a) as well as by the higher volume of the LS than the PES one at $10 \mathrm{~K}$. Unit cell at $300 \mathrm{~K}: a=16.7235(7) \AA, b=$ $21.3275(9) \AA, c=16.7294(7) \AA, \beta=109.419(2)^{\circ}$, and $V=5627.4(4) \AA^{3}$
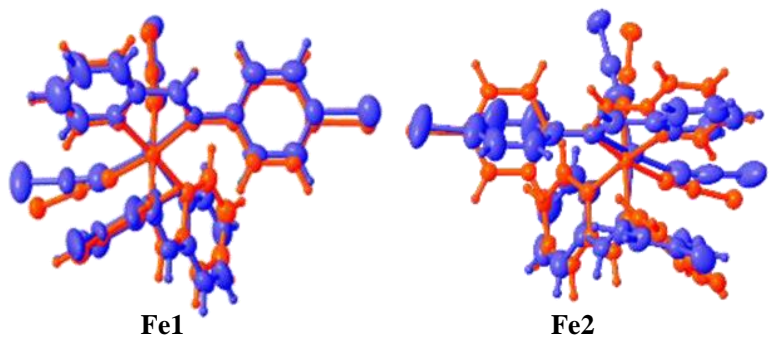

Figure 3. Superposition of the structurally independent two molecular complexes, Fe1 that stands for molecule 1 and Fe 2 that stands for molecule 2 between $\mathrm{HS}$ at $300 \mathrm{~K}$ (blue) and LS at $100 \mathrm{~K}$ (red) showing the huge rotation and motion of ligands in Fe2.

From LS $(80 \mathrm{~K})$ to quenched $\mathrm{HS}(80 \mathrm{~K})$, the modification of the trigonal distortion $(\Delta \Theta)$ is $96.6^{\circ}$ and $122.8^{\circ}$ for $\mathrm{Fe} 1 \mathrm{~N}_{6}$ and $\mathrm{Fe} 2 \mathrm{~N}_{6}$ octahedrons respectively. The trigonal distortion is known 
to be connected to the T(LIESST) value, the higher the distortion the higher $\mathrm{T}$ (LIESST) [5a]. According to the empirical relationship between $\Delta \Theta$ and $T$ (LIESST) in the family with bidentate ligands, the $\mathrm{T}($ LIESST) is expected to be $110 \mathrm{~K}$ for this new complex 1 (Figure S5), which means the observed T(LIESST) of $109 \mathrm{~K}$ from photomagnetic measurements fits here perfectly with the calculated one from structural data. In other words, the high $\mathrm{T}$ (LIESST) observed here mainly originates in the high trigonal distortion of the coordination sphere.

Despite SCO originates at the scale of the coordination sphere, all scales must be considered in the context of a structure- property correlation $[3,12]$. Above the coordination sphere, the molecular scale shows in the present case a very singular behavior. Indeed, as illustrated by the superposition of the atomic positions between HS and LS (Figure 3), one of the phenyl rings in Fe2 entity rotates by around $67^{\circ}$ at the SCO. This spectacular and reversible rotation in the crystalline state is also observed at a fixed temperature when comparing the quenched HS and the LS at $80 \mathrm{~K}$ (Figure S6), which suggests that this feature is linked to the SCO. Furthermore, DSC measurement exhibits clearly only one peak (no other transition detectable and no convolution) which confirms that the variation of the ligand configuration may be concomitant with the SCO (Figure S7). The superposition of molecules at different temperatures (Figure S8), also supports that the variation of the ligand configuration is concomitant with the SCO. It is quite common that SCO is coupled to structural events, like the motion of ligands [13], phase transition [14] or order-disorder phenomena [15]. However, a huge rotation of ligands as observed here is quite rare in SCO materials, especially when reversible, though already reported in association with different processes [16]. This kind of single- crystal to single-crystal transformations without symmetry- breaking is even rare in molecular solids, as a general consideration. Reaching 100\% PES appears difficult but the similarity between the unit-cell parameters of the quenched HS and PES (Table S4) clearly indicates both correspond to the same crystal structure, which also suggests that the photo-driven rotation of the phenyl ring is associated to the SCO.

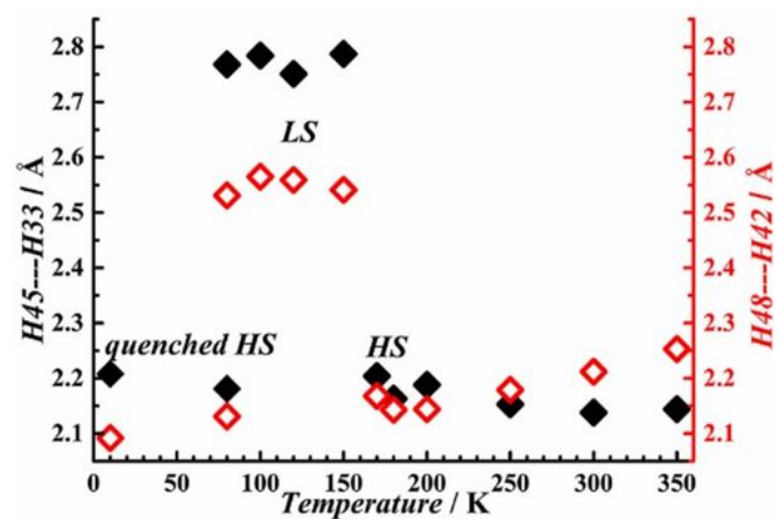

Figure 4. The temperature dependence of the shortest intermolecular (filled rhombus) and intramolecular (empty rhombus) $\mathrm{H}---\mathrm{H}$ contacts showing the SCO behavior, quenched $\mathrm{HS}$ points at $80 \mathrm{~K}$ and $10 \mathrm{~K}$ are obtained by rapid cooling from $300 \mathrm{~K}$.

Looking at the upper physical scale within the crystal, it is clear that the huge conformational ligand variation at the SCO strongly modifies the inter-atomic interactions. At $300 \mathrm{~K}$, in $\mathrm{HS}$, very short contacts include intramolecular and intermolecular $\mathrm{H}-$ - $\mathrm{H}$ ones as short as $2.212 \AA$ and $2.138 \AA$, respectively (Table S3) as well as $S$---S and $\pi_{p y} \cdots \pi_{p y}$ as evidenced by Hirshfeld surface (Figure S9) [17]. These short distances increase dramatically from $170 \mathrm{~K}$ (HS) to $150 \mathrm{~K}$ (LS) (Figure 4). In addition, it is worth noting that these two $\mathrm{H}-\mathrm{H}$ short contacts evolves from $300 \mathrm{~K}$ to $170 \mathrm{~K}$ in a manner to be relatively equal in length just before the SCO (Figure 4). Since the conformation of the PM-BrA ligand when not coordinated is, according to its crystal structure, strongly driven by $\mathrm{H}-\mathrm{H}$ contacts [18], it is highly probable that this situation favors the rotation of the ligand. The modifications of the inter- atomic contact topology at the SCO, including the significant motion of NCS ligands (Figure 3), therefore probably leads the phenyl ring to an unstable position (Figure S10), where it may easily be perturbed by external stimuli. Note that there is no such conformational change in the manganese compound 2 (Figure $\mathrm{S} 11$ ), also confirming that the phenyl rotation is indeed associated to the SCO. The large variations of intermolecular contacts within the solid seem to be closely linked to the expansion of the unit cell volume from HS to LS since the above significant modifications of the inter-atomic contacts induce an expansion of the lattice along the $c$ and [101] directions (Figure S12).

The ease with which the HS is quenched below $80 \mathrm{~K}$ makes that, for technical reasons, PXRD was used instead of SCXRD. Hence, the PXRD experiments at $15 \mathrm{~K}$ using light irradiation to convert from LS to PES, were performed to explore the variation of unit-cell volume in the light-induced regime. As seen in Figures $2 \mathrm{~b}$ and S16, the strongly anisotropic variation of unit-cell parameters that issues in the increase of the unit-cell volume at the thermal SCO is also observed from PES to LS.

In summary, the present compound exhibits very unusual and impressive features such as: i) a reverse (and reversible) expansion of the unit cell volume from HS to LS, never reported so far, ii) a thermo- and light-induced rotation of one phenyl within the crystal that is concomitant to the SCO, iii) one of the highest $\mathrm{T}($ LIESST) known so far that is probably connected to the high energy cost of the phenyl rotation and, last, iv) a one-step SCO despite multiple independent iron sites which is also quite unusual even though already observed [19]. Note that, spectacularly, the volume expansion and the phenyl rotation are fully reversible in the solid state which reveals the robustness and flexibility of molecular based materials.

It is shown here that the volume variation associated with a spin conversion from HS to LS does not always correspond to a decrease but can correspond, on the contrary, to an increase in volume. Therefore, in future researches and development on SCO materials, it should be taken into account that the volume modification associated to the SCO can be negative or positive depending on the compound but independently of the sense of the conversion (HS to LS or LS to HS). This counter-intuitive feature extends the fields of interest and probably of application of the SCO phenomenon.

\section{Acknowledgements}

WBG wishes to acknowledge the China Scholarship Council (201708310106). This work was supported by the Labex Amadeus of the University of Bordeaux, the French PIA project "Lorraine Université d'Excellence", reference ANR-15-IDEX-04- LUE, the CPER (SusChemProc) and the GdR MCM-2: 
Magnétisme et Commutation Moléculaires. We are grateful for measurement time on the X-ray diffraction platform PMD2X of the Institut Jean Barriol and at the X-ray diffraction facilities of ICMCB.

Keywords: spin-crossover $\cdot$ unit cell volume $\cdot$ rotation of phenyl ring $\bullet$ Photo-excited states $\bullet$ phase transition $\bullet$ molecular crystals

[1] a) M. A. Halcrow, Spin-Crossover Materials Properties and Applications Wiley, Chichester, 2013; b) P. Gütlich, H. A. Goodwin, Spin Crossover in Transition Metal Compounds II, Springer, Heidelberg, 2004, pp. 1-47; c) P. Gütlich, Y. Garcia, T. Woike, Coord. Chem. Rev. 2001, 219, 839 879.

[2] a) J.-F Létard, P. Guionneau, L. Goux-Capes, Spin Crossover Transition Metal Compounds III, Springer, Berlin, 2004, pp. 221 -249; b) M. Ruben, K. S. Kumar, Angew. Chem. Int. Ed. 10.1002/anie.201911256.

[3] P. Guionneau, Dalton Trans. 2014, 43, 382-393.

[4] a) V. Legrand, S. Pillet, H. P. Weber, M. Souhassou, J.-F Létard, P. Guionneau, C. Lecomte, J. Appl. Cryst. 2007, 40, 1076-1088; b) A, Grosjean, P. Négrier, P. Bordet, C. Etrillard, D. Mondieig, S. Pechev, E. Lebraud, J.-F Létard, P. Guionneau, Eur. J. Inorg. Chem. 2013, 5-6, 796802.

[5] a) M. Marchivie, P. Guionneau, J.-F Létard, D. Chasseau, Acta Cryst. 2005. B61, 25-28; b) M. Marchivie, P. Guionneau, J. A. K. Howard, G. Chastanet, J.-F Létard, A. E. Goeta, D. Chasseau, J. Am. Chem. Soc. 2002, 124, 2, 194-195; c) M. Cammarata, R. Bertoni, M. Lorenc, H. Cailleau, S. D. Matteo, C. Mauriac, S. F. Matar, H. Lemke, M. Chollet, S. Ravy, C. Laulhé, J.-F Létard, E. Collet, Phys. Rev. Lett. 2014, 113, 227402.

[6] R. Bertoni, M. Lorenc, H. Cailleau, A. Tissot, J. Laisney, M.-L. Boillot, L. Stoleriu, A. Stancu, C. Enachescu, E. Collet, Nat. Mat. 2016, 15, 606610.

[7] a) J.-F Létard, P. Guionneau, E. Codjovi, O. Lavastre, G. Bravic, D. Chasseau, O. Kahn, J. Am. Chem. Soc. 1997, 119, 10861-10862; b) J.- F Létard, P. Guionneau, L. Rabardel, J. A. K. Howard, A. E. Goeta, D. Chasseau, O. Kahn, Inorg. Chem. 1998, 37, 17, 4432-4441; c) E. Tailleur, M. Marchivie, N. Daro, G. Chastanet, P. Guionneau, Chem. Commun. 2017, 53, 4763-4766.

[8] S. Lakhloufi, M. H. Lemée-Cailleau, G. Chastanet, P. Rosa, N. Daro, P. Guionneau, Phys. Chem. Chem. Phys. 2016,18, 28307-28315.

[9] a) M. Marchivie, P. Guionneau, J.-F Létard, D. Chasseau, J. A. K. Howard, J. Phys. Chem. Solids 2004, 65, 17-23; b) H. Wang, C. Desplanches, Ph. Dagault, J.-F Létard, Dalton Trans. 2014, 43, 1534615350 ; c) L. J. Kershaw Cook, F. L. Thorp-Greenwood, T. P. Comyn, O. Cespedes, G. Chastanet, M. A. Halcrow, Inorg. Chem. 2015, 54, 63196330; d) V. Gómez, C. Sáenz de Pipaón, P. Maldonado-Illescas, J. C. Waerenborgh, E. Martin, J. Benet-Buchholz, J. R. Galán-Mascarós, J. Am. Chem. Soc. 2015, 137, 11924-11927; d) N. Paradis, G. Chastanet, T. Palamarciuc, P. Rosa, F. Varret, K. Boukheddaden, J.-F Létard, J. Phys. Chem. C 2015, 119, 20039 -20050; f) V. García-López, M. Palacios-Corella, S. Cardona-Serra, M. Clemente-León, E. Coronado, Chem. Commun. 2019, 55, 12227-12230; g) H. Wang, C. Baldé, A. Grosjean, C. Desplanches, P. Guionneau, G. Chastanet, Dalton Trans. 2018, 47, 14741-14750; h) T. Delgado, A. Tissot, L. Guénée, A. Hauser, F. J. Valverde-MuÇoz, M. Seredyuk, J. A. Real, S. Pillet, E. E. Bendeif, C. Besnard, J. Am. Chem. Soc. 2018, 140, 12870-12876; i) J. Weihermgller, S. Schlamp, B. Dittrich, B. Weber, Inorg. Chem. 2019, 58, 1278-1289.

[10] a) G. Chastanet, C. Desplanches, C.Baldé, P. Rosa, M. Marchivie, P. Guionneau, Chem. Sq. 2018, 2, 2; b) G. Chastanet, M. Lorenc, R. Bertoni, C. Desplanches, C. R. Chim. 2018, 21, 1075-1094.

[11] R. Kulmaczewski, E. Trzop, L. J. Kershaw Cook, E. Collet, G. Chastanet, M. A. Halcrow, Chem. Commun. 2017, 53, 13268-13271.

[12] E. Collet, P. Guionneau, C. R. Chim. 2018, 21, 1133-1151.

[13] a) A. Hauser, F. J. Valverde-Muñoz, M. Seredyuk, J. A. Real, S. Pillet, E. E. Bendeif, C. Besnard, J. Am. Chem. Soc. 2018, 140, 40, 12870-12876; b) M. A. Halcrow, Chem. Soc. Rev. 2011, 40, 4119-4142.
[14] M. Shatruk, H. Phan, B. A. Chrisostomo, A. Suleimenova, Coord. Chem. Rev. 2015, 289, 62-73; b) N. Bréfuel, H. Watanabe, L. Toupet, J. Come, N. Matsumoto, E. Collet, K. Tanaka, J.P. Tuchagues, Angew. Chem. Int. Ed. 2009, 48, 9304-9307.

[15] a) G. S. Matouzenko, A. Bousseksou,S. A. Borshch, M. Perrin, S. Zein, L. Salmon, G. Molnar, S. Lecocq, Inorg. Chem. 2004, 43, 227-236; b) G. A. Craig, J. S. Costa, O, Roubeau, S. J. Teat, G. Aromí, Chem-Eur J 2011, 17, 3120-3127; c) D. Chernyshov, M. Hostettler, K. W. Törnroos, H. B. Bürgi, Angew. Chem. Int. Ed. 2003, 42, 3825-3830.

[16] a) C. Bartual-Murgui, Rosa Diego, Sergi Vela, Simon J. Teat, Olivier Roubeau, Guillem Aromí, Inorg. Chem. 2018, 57, 11019-11026; b) J. Sánchez Costa, S. Rodríguez-Jiménez, G. A. Craig, B. Barth, C. M. Beavers, S. J. Teat, G. Aromí, J. Am. Chem. Soc. 2014, 136, 3869-3874.

[17] a) F. L. Hirshfeld, Their. Chim. Acta 1977, 44, 129-138; b) J. J. McKinnon, M. A. Spackman, A. S. Mitchell, Acta Cryst. B 2004, 60, 627-668; c) M. A. Spackman, D. Jayatilakaa, Cryst. Eng. Comm. 2009, 11, 19-32.

[18] N. Diko, S. J. Zamisa, H. B. Friedrich, M. L. Shozi, Z. Kristallogr. NCS 2019; 234(5), 1069-1070.

[19] N. Pittala, F. Thétiot, C. Charles, S. Triki, K. Boukheddaden, G. Chastanet, M. Marchivie, Chem. Commun, 2017, 53, 8356-8359. 
Entry for the Table of Contents (Please choose one layout)

Layout 2:

\section{COMMUNICATION}

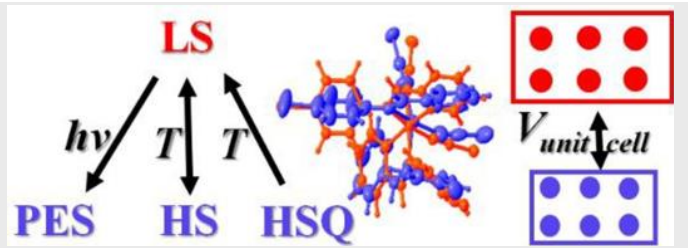

An unprecedented reverse and reversible volume modification in crystals of the molecular complex $\left[\mathrm{Fe}(\mathrm{PM}-p \mathrm{BrA})_{2}(\mathrm{NCS})_{2}\right]$ is observed both for the thermal and the photo-induced spin-crossover processes. Probably linked here to a structural singularity, i.e. an impressive phenyl ring rotation into the crystal, the increase in volume from HS to LS nevertheless opens up new prospects for spin transition based materials.
Wenbin GUO, Nathalie DARO,

Sébastien PILLET, Mathieu MARCHIVIE, El-Eulmi BENDEIF, Elodie

TAILLEUR, Kittipong CHAINOK,

Dominique DENUX, Guillaume CHASTANET*, Philippe GUIONNEAU*

Page No. - Page No.

Unprecedented Reverse Volume Expansion in Spin-Transition Crystals 